\title{
Acute phencyclidine administration induces c-Fos-immunoreactivity in interneurons in cortical and subcortical regions.
}

Mona E. Hervig ${ }^{1,2 *}$, Morten S. Thomsen ${ }^{1,3}$, Imre Kalló ${ }^{4}$, and Jens D. Mikkelsen ${ }^{1 *}$

\author{
${ }^{1}$ Neurobiology Research Unit, Copenhagen University Hospital, Rigshospitalet, Copenhagen, \\ Denmark \\ ${ }^{2}$ Research Laboratory for Stereology and Neuroscience, Bispebjerg Hospital, Copenhagen, \\ Denmark
}

${ }^{3}$ Department of Drug Design and Pharmacology, Faculty of Health and Medical Sciences, University of Copenhagen, Denmark

${ }^{4}$ Department of endocrine neurobiology, Institute of Experimental Medicine, Hungarian Academy of Sciences, Budapest, Hungary

\author{
*Correspondence \\ Mona El-Sayed Hervig, PhD \\ Research Laboratory for Stereology and Neuroscience \\ Bispebjerg University Hospital \\ Bispebjerg Bakke 23, building 11B 2nd floor \\ 2400 Copenhagen \\ E-mail:mona.el-sayed@regionh.dk
}




\section{ABSTRACT}

Dysfunction of N-Methyl-D-aspartate receptors (NMDARS) is believed to underlie some of the symptoms in schizophrenia, and non-competitive NMDAR antagonists (including phencyclidine (PCP)) are widely used as pharmacological schizophrenia models. Furthermore, mounting evidence suggests that impaired $\gamma$-aminobutyric acid (GABA) neurotransmission contributes to the cognitive deficits in schizophrenia. Thus alterations in GABAergic interneurons have been observed in schizophrenia patients and animal models. Acute systemic administration of PCP increases levels of c-Fos in several cortical and subcortical areas, but whether such induction occurs in specific populations of GABAergic interneuron subtypes still remains to be established. We performed an immunohistochemical analysis of the PCP-induced c-Fos-immunoreactivity (IR) in parvalbumin and calbindin interneuron subtypes in the cortex and thalamus of rats. A single dose of PCP (10 mg/kg, s.c.) significantly increased total number of c-Fos-IR in: 1$)$ the prelimbic, infralimbic, anterior cingulate, ventrolateral orbital, motor, somatosensory and retrosplenial cortices as well as the nucleus accumbens, CA1 field of hippocampus and mediodorsal thalamus; 2) parvalbumin-IR cells in the ventrolateral orbitofrontal and retrosplenial cortices and CA1 field of hippocampus; and 3) calbindin-IR cells in the motor cortex. Overall, our data indicate that PCP activates a wide range of cortical and subcortical brain regions and that a substantial part of this activation is present in GABAergic interneurons in certain regions. This suggests that the psychotomimetic effect of PCP may be mediated via GABAergic interneurons.

Keywords phencyclidine, schizophrenia, prefrontal cortex, interneurons, c-Fos, NMDA 


\section{Abbreviations}

BSA, bovine serum albumin; $C A 1$, field $C A 1$ of the hippocampus; $C B$, calbindin; $\mathrm{Cg} 1$, cingulate cortex 1; CPu, caudate putamen; DAB, diaminobenzidine; GABA, $\gamma$-aminobutyric acid; GAD67, glutamic acid decarboxylase 67; IL, infralimbic cortex; IR, immunoreactivity; M1/M2, primary and secondary motor cortex; MD, mediodorsal thalamus; mPFC, medial prefrontal cortex; NAc, nucleus accumbens; NMDAR, N-Methyl-D-aspartate receptor; PBS, phosphate-buffered saline; PCP, phencyclidine; PFC, prefrontal cortex; PrL, prelimbic cortex; PV, parvalbumin; RS, retrosplenial cortex; S1, primary somatosensory cortex; SEM, standard error of the mean; TX, Triton X-100; VLO, ventrolateral orbital cortex. 


\section{INTRODUCTION}

Deficient glutamate-mediated excitatory neurotransmission through N-Methyl-D-aspartate receptors (NMDARs) is believed to underlie some of the symptoms seen in patients with schizophrenia (Javitt et al. 2012). The NMDAR hypofunction hypothesis of schizophrenia arose from studies showing that a single dose of non-competitive NMDAR antagonists (phencyclidine (PCP) and ketamine) evoked schizophrenia-like symptoms in healthy individuals and exacerbated symptoms in schizophrenia patients (Luby et al. 1959; Bakker and Amini 1961; Javitt and Zukin 1991; Krystal et al. 1994; Lahti et al. 1995; Malhotra et al. 1997; Adler et al. 1999). Non-competitive NMDAR antagonists also induce cognitive and sensory motor abnormalities in experimental animals (Castellani and Adams 1980; Haggerty et al. 1984; Javitt et al. 1996; Malhotra et al. 1997; Newcomer et al. 1999).

Imaging studies have revealed lower metabolic activity in the prefrontal cortex (PFC), hippocampus, ventral striatum and thalamus in patients with schizophrenia (Morris et al. 2005), emphasising the involvement the cortico-limbo-thalamic circuitry in schizophrenia. The PFC is an important site for psychosis and cognitive problems related to schizophrenia, and it has been shown that acute systemic administration of ketamine or PCP rapidly increases PFC metabolic activity in parallel with PFC-related psychotic symptoms in healthy individuals (Vollenweider et al. 1997; Breier et al. 1997; Lewis, 2012). Likewise, studies in rats have shown rapid increases in PFC neuronal firing and expression of immediate-early genes following acute NMDAR antagonism (including PCP) (Suzuki et al. 2002; Gao et al. 1993, 1998). This increase in PFC activity has been observed to be followed by a delayed depression of activity over a 24 hours period followed (Gao et al. 1993, 1998), which may be relevant to the decrease in PFC activity 
seen in schizophrenia patients. Furthermore, PFC synchronous gamma-oscillations important for cognitive function are impaired in schizophrenia (Cho et al. 2006; Uhlhaas and Singer, 2010; Minzenberg et al. 2009, 2010; Gonzalez-Burgos and Lewis, 2012). Importantly, those neurons mediating the psychotomimetic actions of non-competitive NMDAR antagonists are still unknown. Another important aspect to take into account is that also subcortical areas are relevant for PCP- or MK-801-mediated changes in activity and neurotransmission (Suzuki et al. 2002; Jodo et al. 2005; Amargós-Bosch et al. 2006; López-Gil et al. 2007). Several studies point to the mediodorsal and centromedial thalamic nuclei, that are reciprocally connected to the PFC (Berendse and Groenewegen, 1991; Fuster, 2008), to be of major importance in mediating the effects of non-competitive NMDAR antagonists (Kargieman et al. 2007; Santana et al. 2011; Kiss et al. 2011; Celada et al. 2013).

In addition to abnormal glutamatergic neurotransmission, mounting evidence suggests that impaired $\gamma$-aminobutyric acid (GABA)ergic neurotransmission, at least in part, mediates the cognitive deficits in schizophrenia (Lewis et al. 2008; Lewis et al. 2012; Gonzalez-Burgos et al. 2015). Coordinated activity of excitatory pyramidal cells and GABAergic interneurons, in particular via fast-spiking parvalbumin (PV) interneurons, govern the synchronisation of gammaoscillations within the PFC (Gonzalez-Burgos and Lewis, 2012), and NMDARs expressed in PV interneurons are critical for induction of gamma-oscillations and behaviour (Sohal et al. 2009; Carlén et al. 2012; Belforte et al. 2010).

Post-mortem studies in the PFC of schizophrenia patients have consistently reported reduced levels of the GABA synthesising enzyme, glutamic acid decarboxylase 67 (GAD67) as well as reduced levels of PV interneuron immunoreactivity and mRNA (Akbarian et al. 1995; Volk et al. 2000; Eyles et al. 2002; Woo et al. 2008; Hashimoto et al. 2008). Further, PV cells exhibit abnormalities in several molecular features that are likely to be critical to their function as reviewed by Lewis (2014). Similarly, repeated administration of non-competititve NMDAR 
antagonists (PCP, ketamine or MK-801) decreases the expression of GAD67 and PV in cortical GABAergic neurons in primary cortical neurons, rat and monkey (Cochran et al. 2003; Keilhoff et al. 2004; Rujescu et al. 2006; Behrens et al. 2007; Morrow et al. 2007) and manipulating GABAergic precursor neurons in the PFC can ameliorate PCP-induced cognitive changes in mice (Tanaka et al. 2011). Genetic deletion of the essential NMDAR1 subunit in PV interneurons in mice leads to disinhibition of cortical excitatory neurons, altered neuronal synchrony, and produces working memory deficits (Korotkova et al. 2010; Belforte et al. 2010; Carlén et al. 2012). Changes in other mRNA levels of GABAergic interneuron subtypes such as calbindin (CB), neuropeptide $\mathrm{Y}$, somatostatin, vasoactive intestinal peptide and cholecystokinin also have been observed in the PFC of schizophrenia patients (Hashimoto et al. 2003, 2008; Fung et al. 2010, 2014).

A range of NMDA antagonists has been used for NMDA hypofunction modelling in animals and humans (Gilmour et al. 2012). In this study, we chose to use the non-competitive NMDAR antagonist PCP, since this drug has been widely used for modelling NMDA hypofunction in schizophrenia and, as described above, has shown comparable effects in humans and animals. This potentially support translation of results between animal and human studies. It is wellestablished that acute systemic administration of PCP increases levels of the immediate early gene (IEG) c-Fos in several areas including PFC, hippocampus, nucleus accumbens (NAc) and thalamic nuclei in rodents (Näkki et al. 1996; Sato et al. 1997; Griffiths et al. 1999; Habara et al. 2001; Gotoh et al. 2002; Kargieman et al. 2007; Kargieman et al. 2008; Kalinichev et al. 2008; Santana et al. 2011; Castañe et al. 2015). It has been reported that PCP-induced c-Fos mRNA occurs in GAD67-neurons in the hippocampus, amygdala, as well as somatosensory and retrosplenial cortex (Santana et al. 2011). However, whether this effect occurs in subsets of GABAergic interneurons in cortical and subcortical areas has not been investigated. 
In the present study, we explore whether activation of two largely non-overlapping groups of interneurons (Kawaguchi and Kubota, 1997; Druga, 2009) characterised by their content of the $\mathrm{Ca}^{2+}$-binding proteins PV and CB (DeFelipe, 1997), might be involved in the neuronal response to PCP. To this end, we investigated the c-Fos immunoreactivity (IR) in response to acute systemic PCP (10 mg/kg, s.c.) in these interneuron subtypes in cortical and thalamic regions.

\section{EXPERIMENTAL PROCEDURES}

\section{Animals}

A total number of 17 male Wistar rats (219-239 g; around 12 weeks old) were purchased from Taconic Europe (LI. Skensved, Denmark). The animals were acclimatised under standardised conditions with a 12/12-hr light/dark cycle and free access to food and water for seven days after arrival. All experiments were conducted in accordance with the Declaration of Helsinki, the Danish National Guide for Care and Use of Laboratory animals and the European Communities Council Directive of 24 November 1986 (86/609/EEC).

\section{Drug treatment}

PCP [1-(1-phenylcyclohexyl)piperidine]-hydrochloride (synthesised at the Department of Medicinal Chemistry, Faculty of Pharmaceutical Sciences, Copenhagen University) was dissolved in $0.9 \%$ saline. The rats were injected with PCP $(10 \mathrm{mg} / \mathrm{kg} ; 2 \mathrm{ml} / \mathrm{kg}$, s.c.) or vehicle $(0.9 \%$ saline; $2 \mathrm{ml} / \mathrm{kg}$, s.c.) and returned to their home cage for $60 \mathrm{~min}$ before transcardial perfusion. This particular dose of PCP was chosen since it has been shown to induce c-Fos in cortical and subcortical regions, alter discharge activity in neurons and also induce changes in c-Fos expression in GABAergic interneurons (Kargieman et al. 2007; Santana et al. 2011; Sato et al. 1997; Jodo et al. 2010). 


\section{Transcardial perfusion and fixation}

The rats were deeply anaesthetised with a solution of pentobarbital $(200 \mathrm{mg} / \mathrm{ml})$ and lidocainhydrochloride $(20 \mathrm{mg} / \mathrm{ml})(2 \mathrm{ml} / \mathrm{kg}$, i.p.) and subsequently perfused transcardially with $0.1 \mathrm{M}$ phosphate-buffered saline (PBS) until the blood was flushed followed by $4 \%$ paraformaldehyde in PBS for approximately $10 \mathrm{~min}$. Brains were dissected from the skull, immersed in fixative overnight at $4^{\circ} \mathrm{C}$ and submerged in $30 \%$ sucrose in PBS at $4^{\circ} \mathrm{C}$ for 2 days. The brains were cut in $40 \mu \mathrm{m}$ serial coronal sections in 6 parallel series on a freezing microtome (Bright series 8000; Bright Instrument, Cambridgeshire, UK), and the free-floating sections were stored at $-20^{\circ} \mathrm{C}$ in antifreeze solution $\left(0.01 \mathrm{M} \mathrm{NaH}_{2} \mathrm{PO}_{4}, 0.03 \mathrm{M} \mathrm{Na}_{2} \mathrm{HPO}_{4}, 30 \%\right.$ ethylenglycol, and $30 \%$ glycerol) until use.

\section{Colorimetric immunohistochemistry}

The sections were rinsed for $3 \times 10$ min in PBS, incubated for 10 min in $1 \% \mathrm{H}_{2} \mathrm{O}_{2}$ in PBS to block endogenous peroxidase activity and subsequently incubated for 20 min in PBS with 5\% normal donkey serum, $1 \%$ bovine serum albumin (BSA) and $0.1 \%$ Triton $\mathrm{X}-100$ (TX) to block nonspecific binding sites. The sections were then incubated at $4^{\circ} \mathrm{C}$ overnight with the primary antiserum in PBS with $1 \%$ BSA and $0.1 \%$ TX. After incubation in primary antiserum, the sections were washed for $3 \times 10 \mathrm{~min}$ in PBS with $0.1 \%$ TX (PBS-TX) and incubated for $60 \mathrm{~min}$ in biotin-conjugated secondary antibody diluted 1:1000 in PBS-TX with 1\% BSA, washed for $3 \times 10$ min in PBS-TX and transferred to an avidin-biotin complex solution (\#PK-6100, Vector Laboratories, Burlingame, CA, USA) diluted 1:500 in PBS-TX for 60 min. After washing $10 \mathrm{~min}$ in PBS-TX, PBS, and Tris-HCl $(\mathrm{pH} 7.6)$, the sections were incubated in either: 1$) 0.1 \%$ diaminobenzidine (DAB; Sigma Aldrich, St. Louis, MO, USA) with $0.03 \% \mathrm{H}_{2} \mathrm{O}_{2}$ in Tris- $\mathrm{HCl}$ buffer; or 2) $0.025 \% \mathrm{DAB}$ with $0.015 \% \mathrm{H}_{2} \mathrm{O}_{2}$, $0.075 \%$ nickel sulphate and $5 \mathrm{mM}$ imidazole in Tris-HCl buffer (DAB-nickel) for 10 min. Finally, 
the sections were washed $3 \times 10 \mathrm{~min}$ in PBS. For double-labelling, the procedure was repeated with a different primary antiserum and completed with incubation in $0.1 \%$ DAB with $0.03 \% \mathrm{H} 2 \mathrm{O} 2$ in Tris-HCl buffer for $10 \mathrm{~min}$.

The DAB reaction (orange-brown) was applied for c-Fos-single-labelling and PV- and CB-labelling in double-labelling procedures. The DAB-nickel reaction was applied for c-Fos-labelling in double-labelling procedures producing a black colour localised to the nucleus. In order to obtain optimal double-labelling, c-Fos-IR in sections planned to be $C B+c-F o s$ double-labelled were further silver-gold intensified using the Gallyas method (Liposits et al. 1984) prior to the incubation with CB antibody. The sections were mounted on gelatinized glass slides, dried, and coverslipped in Pertex.

\section{Antibodies}

Primary antisera used and their concentrations were as follows: polyclonal antiserum against cFos (1:8000 for single staining and 1:16000 for double staining), generated in a rabbit with a peptide corresponding to amino acids 2-17 of the rat c-Fos protein in our laboratory and previously characterised (Mikkelsen et al. 1998), polyclonal rabbit antibody against PV (1:6000, \#PC255L; Merck Millipore, Darmstadt, Germany) and monoclonal mouse anti-CB-D-28K antibody (1:20000, \#C9848; Sigma Aldrich, St. Louis, MO, USA).

Biotin-conjugated secondary antibodies were raised in donkey, from Jackson Laboratories (Ben Harbor, ME) and used in a 1:1000 dilution.

\section{Regions of interest}

Prelimbic cortex (PrL), infralimbic cortex (IL), cingulate cortex 1 (Cg1), primary and secondary motor cortex (M1/M2), primary somatosensory cortex (S1) and ventrolateral orbital cortex (VLO) were analysed in sections within $3.72 \mathrm{~mm}$ to $2.52 \mathrm{~mm}$ from bregma (figure 1, left). Nucleus 
accumbens shell (NAc shell) and core (NAc core) as well as caudate putamen ( $\mathrm{CPu}$ ) were analysed in sections within $2.16 \mathrm{~mm}$ to $1.32 \mathrm{~mm}$ from bregma (figure 1, middle). Retrosplenial cortex (RS), field CA1 of the hippocampus (CA1) and mediodorsal thalamus (MD) were analysed in sections within -2.92 $\mathrm{mm}$ to $-3.24 \mathrm{~mm}$ from bregma (figure 1, right) (according to Paxinos and Watson ( $5^{\text {th }}$ ed.) 2004). The counting frames were placed in similar localisations in each region for each neuronal marker. However, there were some differences in the placement of the M1/M2 and S1 counting frames. PV+c-Fos double-stained sections were counted in cortical layers II-V of M1/M2 and S1 - corresponding to the single c-Fos countings (figure 1). In CB+c-Fos double-stained sections, layers III-VI were counted in M1/M2 and S1. Hence, CB-IR cells are a very heterogeneous group of cells including both GABAergic and non-GABAergic cells, which can be distinguished from each other by the IR intensity and localisation. GABAergic CB-IR cells are intensely labelled and localised to cortical layer II-VI, whereas non-GABAergic CB-IR cells are weakly stained and mainly localised in cortical layers II and III (Gonchar and Burkhalter, 1997). Thus the counting frames for $\mathrm{CB}+\mathrm{C}$-Fos-labelled sections were placed to avoid counting the weakly stained CB-IR cells. CB-IR cells in NAc shell and MD are not included in the analysis, since these cells have been shown not to be GABAergic neurons and were therefore not included in the analysis (Hendry and Jones, 1989; Sadikot and Sasseville, 1997).

\section{Semi-quantitative assessment of immunoreactive neurons}

All countings were done by an observer blind to the treatment regimens, and the cells were independently recounted by a second observer. The number of positive cells for each region was averaged from both hemispheres on two adjacent sections. In order to count c-Fos-IR in singlestained sections, $100 \times$ magnified images $(1.027 \mathrm{~mm} \times 0.770 \mathrm{~mm})$ of the area of interest were obtained under bright field illumination in a Zeiss Imager.Z1 microscope and c-Fos-IR cells were counted with Image $1.46 \mathrm{r}$ software by an automated procedure counting particles of 
appropriate size with a specific threshold held constant through all the animals in the experiment. The number of PV-IR and CB-IR cells and cells, which were also c-Fos-IR, were counted manually under bright field illumination in a Zeiss Imager.Z1 microscope (400x magnification) using NewCast software (Visiopharm, Hoersholm, DK) to frame the regions of interest.

The data from single-c-Fos-IR countings are presented as c-Fos-IR per area, whereas the data from double-stainings are presented as the relative numbers of PV-IR and CB-IR neurons, respectively, which were also c-Fos-IR.

In order to obtain a meaningful relative number of c-Fos-IR interneurons, the inclusion criterion number was 15 total PV-IR or CB-IR cells per animal within a particular region. Regions where more than $80 \%$ of the animals had less than 15 interneurons were excluded from analysis and noted as not detectable (N.D.; table 1 and 2). See table 1 for numbers of counted PV-IR and CBIR cells in all regions of interest.

\section{Statistical Analysis}

D'Agostino \& Pearson normality test was performed and c-Fos-IR and PV+c-Fos-IR data were square-root-transformed for obtaining normal distribution. Transformed data (c-Fos-IR and $P V+c-F o s-I R$ data) and non-transformed data ( $C B+C-F o s+I R$ data) were analysed using multiple unpaired t-tests (with and without Welch's correction, respectively) corrected for multiple comparisons with Holm-Sidak post hoc test (obtaining adjusted P-values) (see table 2). Statistical tests and graphs (figures 3, 5, 6, 8 and table 2) were generated using GraphPad Prism version 7.0 for Windows (GraphPad Software, San Diego, USA). All data are presented as mean \pm standard error of the mean (SEM) and P-values less than 0.05 were considered statistically significant. 


\section{RESULTS}

\section{PCP induces C-Fos-IR in cortical areas and MD.}

The number of c-Fos-IR cells per area was counted in sections from rats treated with vehicle (saline; $\mathrm{N}=8$ ) or acute PCP (10 mg/kg; N=9) (figure 2) and Holm-Sidak-corrected multiple t-tests on transformed data were performed to compare vehicle and PCP treated groups. This analysis showed that PCP significantly increased c-Fos-IR in the following regions: $\operatorname{PrL}(P<0.05, t-$ ratio=3.02, $d f=15), I L(P<0.05, t-r a t i o=3.77, d f=15), C g 1(P<0.05, t$-ratio=3.24, $d f=15), V L O$ $(P<0.001, t-r a t i o=11.33, d f=15), M 1 / M 2(P<0.001, t-r a t i o=7.77, d f=15), S 1(P<0.05, t-r a t i o=6.05$, $d f=15), R S(P<0.001, t-r a t i o=5.10, d f=15)$, NAc core $(P<0.05, t$-ratio=2.84, $d f=15), M D(P<0.001$, t-ratio=5.65, $d f=15), C A 1(P<0.05, t-r a t i o=2.191, d f=15)$, but not in , NAc shell and CPu (see table 2 and figure 3).

\section{PCP induces c-Fos-IR in PV-IR cells in the VLO, RS and CA1.}

The number of PV-IR cells and PV+C-Fos-IR cells were counted in sections from the same animals as above (figure 4). The relative number of PV-IR cells co-labelled with nuclear c-Fos-IR, was calculated and Holm-Sidak-corrected multiple t-tests were performed on transformed data to compare the groups (see table 2 and figure 5). This analysis showed that PCP significantly induced c-Fos-IR in PV-IR cells in the VLO $(P<0.001$, t-ratio=7.49, df=15), RS $(P<0.001, t-$ ratio=5.84, $d f=15)$ and $C A 1(P<0.001, t-r a t i o=5.90, d f=15)$. These effects were not due to differences in numbers of PV-IR cells between treatment groups, since no PCP-dependent differences in PV cells numbers were found in these regions (data not shown). No significant PCP-induced effects were found in the PrL, IL, Cg1, M1/M2, S1 and CPu. Very low numbers of PV-IR cells were detected in NAc core and shell and MD, and therefore these areas were not analysed according to selection criteria. 


\section{PCP induces c-Fos-IR in CB-IR cells in M1/M2.}

The number of CB-IR cells and CB+C-Fos-IR cells were counted in sections from the same animals as above (see table 1) (figure 6.A). The relative number of CB-IR cells, which were also c-Fos-IR, was calculated and Holm-Sidak-corrected multiple t-tests were performed to compare the groups (see table 2 and figure 6. A,B). This analysis showed that among the regions examined PCP only induced c-Fos-IR in CB-IR cells in the M1/M2 $(P<0.001, t$-ratio=5.19, df=15). In CB-IR cells in the PrL, IL, Cg1, S1 and VLO c-Fos-IR were not increased by PCP administration. No or an insufficient number of CB-IR cells were detected in NAc core, CPu, RS and CA1.

\section{DISCUSSION}

The present study demonstrates by immunohistochemical analysis that acute PCP stimulates induction of c-Fos in cortical and limbic areas as well as the MD and that a part of this increase is due to activation of the PV interneuron subtype.

\section{PCP-induced c-Fos-IR in the PFC and MD}

We show that acute PCP treatment induces widespread c-Fos-IR in most brain regions examined including cortical, limbic and thalamic regions. More specifically, PCP-induced c-Fos-IR was observed all PFC subregions examined (PrL, IL, Cg1 and VLO) as well as motor cortex, S1, RS, CA1, NAc core and MD. Overall, this observation agrees with previous studies showing that acute PCP administration at the same dose as used here induced elevations in c-Fos mRNA in the PFC, RS, S1, motor cortex and MD (Kargieman et al. 2007; Santana et al. 2011), but not CA1 (Santana et al. 2011). Studies using other doses of PCP or other non-competitive NMDAR antagonists also report c-Fos mRNA or protein elevations in these areas (Habara et al. 2001 (5 mg/kg PCP); Gotoh et al. 2002 (7.5 mg/kg PCP); De Leonibus et al. 2002 (MK-801); Väisänen et al. 2004 (MK-801); 
Imre et al. 2006 (ketamine)). Electrophysiological studies further report that acute noncompetitive NMDAR antagonists (MK-801 and PCP) affects the firing activity in PFC and thalamic neurons in vivo (Jackson et al. 2004; Jodo et al. 2005; Kargieman et al. 2007; Homayoun and Moghaddam, 2007; Santana et al. 2011).

We find significant increases in PCP-induced c-Fos-IR in the NAc core, and not in other striatal regions examined. This is supported by previous studies (Habara et al. 2001), but this finding is not consistent across all studies using NMDA antagonists (Gao et al. 1998 (NAc overall); De Leonibus et al. 2002 (NAc core)). We also find that PCP induces c-Fos-IR in the CA1, which has not previously been found in studies with similar or lower PCP doses (Näkki et al. 1996; Gotoh et al. 2002 Santana et al. 2011), but is in line with previous studies using stronger PCP doses or other NMDA antagonists (Näkki et al. 1996; Väisänen et al. 2004; Imre et al. 2006) supporting this region to be involved in mechanisms underlying NMDA hypofunction.

Interestingly, in addition to what has previously been reported, we find that PCP strongly activates c-Fos in the VLO specifically, which is a region highly functionally coupled to the MPFC through robust reciprocal projections. Our results suggest a dissociable PCP-induced activation of the MPFC versus the VLO, since the VLO is more strongly affected by PCP treatment. This, together with the differences in the c-Fos-IR basal levels of MPFC and VLO, indicate that different mechanisms might contribute to PCP-induced c-Fos-IR in the MPFC versus the VLO, which is likely, given the functional dissociation of these two PFC subregions (Kolb et al. 2004).

Several studies have shown that the PFC and MD are the predominant sites mediating the actions of non-competitive NMDAR antagonists, including changes in neurotransmission and behaviour (Amargós-Bosch et al. 2006; López-Gil et al. 2007; Kargieman et al. 2007; Zhang et al. 2009, 2012; Santana et al. 2011; Kiss et al. 2011; López Hill and Scorza 2012). Furthermore, it has been proposed that PCP acts on the cortico-thalamo-cortical circuit involving the PFC, RS 
and thalamus (Celada et al. 2013). Our observations support the involvement of the PFC, RS and MD in the actions of NMDAR antagonism. Due to the reciprocal connectivity of these areas, one would expect activity of these regions to be coupled. There are, however, some differences in the degree of PCP-induced C-Fos-IR in these regions - suggesting that different mechanisms might contribute to the effects of $\mathrm{PCP}$, or that the primary PCP-mediated activation is at an afferent site that projects stronger to the VLO and RS than the MPFC. Studies have shown that whereas systemic administration of non-competitive NMDAR antagonists leads to PFC and MD hyperactivity, locally injected antagonists in the PFC has no effect on the activity of PFC neurons (Suzuki et al. 2002; Jodo et al. 2005; Kiss et al. 2011) suggesting excitatory inputs to the PFC to be involved in the actions of non-competitive NMDAR antagonists. Further, local MK-801 administration into the MD produces effects similar to systemically injected MK-801 (Kiss et al. 2011) indicating that non-competitive NMDAR antagonists act on circuit level at thalamic areas. Since we observe increased c-Fos-IR in the motor cortex and S1 by PCP treatment, these areas may also contribute to the PCP-induced increased inputs to the PFC.

Since $70-80 \%$ of neocortical neurons are excitatory pyramidal neurons and $20-30 \%$ are interneurons (Markram et al. 2004), these overall increases in c-Fos-IR observed in the present study are likely to represent mainly excitatory activity of pyramidal neurons, but a fraction of the activated neurons may also include GABAergic interneurons.

\section{PCP-induced c-Fos-IR in GABAergic interneurons}

We show that, as opposed to CB-IR neurons, the c-Fos-IR in PV-IR neurons is affected by PCP treatment in several regions, supporting a specific role for PV interneurons in the effects of NMDAR antagonism.

The PV positive subgroup of interneurons has received much attention in relation to its involvement in schizophrenia (Gonzalez-Burgos and Lewis, 2012). In rat cortex, PV is expressed 
in around $50 \%$ of GABAergic interneurons (Gonchar and Burkhalter, 1997). Furthermore, PV cells innervate both pyramidal neurons and other interneurons (Druga, 2009). Thus PV cells play a central role in coordinating the activity of excitatory pyramidal cells and GABAergic interneurons governing the synchronisation of cortical gamma-oscillations (Gonzalez-Burgos and Lewis, 2012), and it has been shown that the induction of gamma-oscillations is dependent on NMDARs expressed in PV interneurons (Sohal et al. 2009; Carlén et al. 2012). Although the mPFC contains the PV neurons generating and regulating gamma-oscillations and is probably the site important in schizophrenia patients (Beasley and Reynolds, 1997; Danos et al. 1998; Zhang and Reynolds 2002; Cho et al. 2006; Uhlhaas and Singer 2010; Minzenberg et al. 2009, 2010) and animal models (Cochran et al. 2003; McKibben et al. 2010; Thomsen et al. 2010), we found no PCPinduced c-Fos-IR in PV-IR cells in the mPFC areas. Consistently, a previous study found no increase in c-Fos mRNA in GABAergic neurons in the MPFC (Santana et al. 2011). It is likely that the lack of increased activity in the PV interneurons in the MPFC may be due to PCP directly blocking the NMDARs in these PV cells, which may contribute to the overall increased c-Fos-IR in the MPFC, as described above, due to lack of control by local PV interneurons. Interestingly, in contrast to the MPFC, we observe PCP-induced c-Fos-IR in PV cells in the VLO, which is not only closely interconnected with the mPFC, but also to the MD (Price 2007). Thus over-excited PV cells in the VLO may lead to altered excitatory inputs to the MPFC and MD and hence contribute to altered activity in excitatory neurons in these regions. It is relevant to note that the c-Fos-IR basal level of PV cells in the VLO is low compared to the MPFC subregions (PrL, IL and Cg1) and that the number of PCP-induced c-Fos-IR cells in the VLO is actually at the level of the basal levels of these mPFC subregions. This indicates that GABAergic neurotransmission at rest in the VLO is different from that in the MPFC. Based on this observation, it would be interesting to further investigate differences in the GABAergic neurotransmission in the mPFC versus the orbitofrontal cortex. 
In the present study, we also observe that PCP highly induces c-Fos-IR in PV-IR cells localised in the RS and CA1. Both regions are thought to be affected in schizophrenia (Morris et al. 2005; Bluhm et al. 2009) and connected to the PFC (Van Groen and Wyss, 2003; Price, 2007). Previous studies have shown that PCP administration increases the c-Fos mRNA expression in both glutamatergic and GAD67 positive neurons in the RS and in GAD67 positive neurons in the CA1 (Kargieman et al. 2007; Santana et al. 2011). This corresponds to our observations, where we see PCP highly inducing c-Fos-IR overall and in PV-IR neurons in the RS, whereas PCP moderately induces overall c-Fos-IR, but strongly induces c-Fos-IR in PV-IR cells, in the CA1, which is a region that innervates the RS (Cenquizca and Swanson, 2007).

Celada et al. (2013) has proposed that PCP acts on GABAergic neurons in the reticular nucleus of thalamus, which in turn disinhibits relay neurons of thalamic nuclei. These relay neurons would subsequently increase the excitatory inputs to both GABAergic and glutamatergic cells in S1 and RS and thus potentially exert dual influence on PFC pyramidal cells by direct excitation and indirect inhibition via local GABAergic interneurons (Celada et al. 2013). We find PCPinduced c-Fos-IR in neurons overall in the S1 and RS and in GABAergic PV neurons in the RS, but not the S1 (as reported in (Santana et al. 2011)). This may either be due to lack of effect of PCP in the $\mathrm{S} 1$ or to differences in the cortical layers examined, since we examined the cortical layers II-V as opposed to exclusively the inner layers (IV-VI) (Santana et al. 2011).

Overall, these findings show that PCP increases the activity of PV-IR neurons in areas directly connected to the MPFC, but not the MPFC itself, which may support that PCP mediates its effect indirectly via subcortical projections to the mPFC (Jodo, 2013; Celada et al. 2013). However, it is likely that the lack of increased activity in the MPFC PV interneurons may be due to PCP directly blocking the NMDARs in these PV cells, since PCP has been shown to act directly on GABAergic interneurons in the PFC (Homayoun and Moghaddam 2007). Together with the increased 
activity in the input systems, including in particular the VLO as well as the MD, S1 and RS, this may contribute to the increased mPFC network activity, since it is not compensated by PV interneuron-mediated inhibition. Thus this results in a disturbance of the excitatory-inhibitory balance as proposed to be relevant in the NMDA hypofunction model of schizophrenia (Kehrer et al. 2008). In theory this can also be the case for other regions, e.g. the motor cortex and S1, where we observe PCP-induced c-Fos-IR overall, but lack of activity in the PV neurons. However, conclusions regarding these regions will be more speculative, since these have not been investigated as intensively as the PFC in regard to the NMDA hypofunction model.

Here we investigated the effects of acute blocking of NMDARs on c-Fos expression. Despite the relevance of investigating acute effects, we acknowledge the importance of investigating the effects of sub-chronic PCP administration on regional c-Fos expression, since this is a model widely used for mimicking a range of schizophrenia-related symptoms (Meltzer et al. 2011, 2013). It is also important to investigate other immediate early genes suggested to be relevant to schizophrenia such as activity-regulated cytoskeleton-associated protein, Homer 1 and deltaFosB (Purcell et al. 2014; lasevoli et al. 2014; Dietz et al. 2014).

\section{Conclusion}

The NMDA hypofunction model may not elucidate the highly complex set of mechanisms leading to schizophrenia in humans, but it can help our understanding of the mechanisms leading to acutely induced schizophrenia-like states in humans. The present study shows that PCP induces a diverse c-Fos-IR pattern in specific GABAergic interneuron subtypes in cortical and subcortical brain areas. PV-IR neurons that are thought to be highly implicated in schizophrenia (GonzalezBurgos and Lewis, 2012) show increased PCP-induced c-Fos-IR in the orbitofrontal cortex and limbic regions, but not in the mPFC. Overall, our data indicate that PCP exerts a profound 
disruption of cortico-limbo-thalamic networks partly by altering the activity of specific GABAergic interneuron subtypes which opens the possibility that the psychotomimetic effects of PCP may reside in its effect on GABAergic interneurons. This supports the hypothesis that GABAergic interneurons are prime targets in NMDAR antagonism.

\section{Acknowledgements}

This work was supported by the Danish Medical Research Council, the Strategic Research Council (COGNITO), and the Lundbeck Foundation. 


\section{REFERENCES}

Adler CM, Malhotra AK., Elman I, Goldberg T, Egan M, Pickar D, Breier A (1999), Comparison of ketamineinduced thought disorder in healthy volunteers and thought disorder in schizophrenia. Am J Psychiatry 156(10): 1646-9.

Akbarian S, Kim JJ, Potkin SG, Hagman JO, Tafazzoli A, Bunney WE, and Jones EG (1995), Gene expression for glutamic acid Is reduced without loss of neurons in prefrontal cortex of schizophrenics. Arch Gen Psychiatry 52(4):258-266.

Amargós-Bosch M, López-Gil X, Artigas F, Adell A (2006), Clozapine and olanzapine, but not haloperidol, suppress serotonin efflux in the medial prefrontal cortex elicited by phencyclidine and ketamine. Int J Neuropsychopharmacol 9(5):565-73.

Bakker CB, Amini FB (1961), Observations on the psychotomimetic effects of Sernyl. Compr Psychiatry 2: 26980.

Beasley CL, Reynolds, GP (1997), Parvalbumin-immunoreactive neurons are reduced in the prefrontal cortex of schizophrenics. Schizophr Res, 24(3):349-55.

Beasley CL, Zhang ZJ, Patten I, Reynolds GP (2002), Selective deficits in prefrontal cortical GABAergic neurons in schizophrenia defined by the presence of calcium-binding proteins. Biol Psychiatry 52(7):708-15.

Behrens MM, Ali SS, Dao DN, Lucero J, Shekhtman G, Quick KL, Dugan LL (2007), Ketamine-induced loss of phenotype of fast-spiking interneurons is mediated by NADPH-oxidase. Science 318(5856):1645-7.

Belforte JE, Zsiros V, Sklar ER, Jiang Z, Yu G, Li Y, Quinlan EM, Nakazawa K (2010), Postnatal NMDA receptor ablation in corticolimbic interneurons confers schizophrenia-like phenotypes. Nat Neurosci 13(1):7683. 
Berendse HW, Groenewegen HJ (1991), Restricted cortical termination fields of the midline and intralaminar thalamic nuclei in the rat. Neuroscience 42(1):73-102.

Bluhm RL, Miller J, Lanius RA, Osuch EA, Boksman K, Neufeld RW, Théberge J, Schaefer B, Williamson PC (2009), Retrosplenial cortex connectivity in schizophrenia. Psychiatry Res, 174(1):17-23.

Breier A, Malhotra AK, Pinals DA, Weisenfeld NI, Pickar D (1997), Association of ketamine-induced psychosis with focal activation of the prefrontal cortex in healthy volunteers. Am J Psychiatry 154(6): 805-11.

Carlén M, Meletis K, Siegle JH, Cardin JA, Futai K, Vierling-Claassen D, Rühlmann C, Jones SR, Deisseroth K, Sheng M, Moore Cl, Tsai LH (2012), A critical role for NMDA receptors in parvalbumin interneurons for gamma rhythm induction and behavior. Mol Psychiatry 17(5):537-48.

Castañé A, Santana N, Artigas F (2015), PCP-based mice models of schizophrenia: differential behavioral, neurochemical and cellular effects of acute and subchronic treatments. Psychopharmacology (Berl) 232(21-22).

Castellani S, Adams PM (1980), Effects of dopaminergic drugs on phencyclidine-induced behaviour in the rat. Neuropharmacology 20:371-374.

Celada P, Lladó-Pelfort L, Santana N, Kargieman L, Troyano-Rodriguez E, Riga MS, Artigas F (2013), Disruption of thalamocortical activity in schizophrenia models: relevance to antipsychotic drug action. Int J Neuropsychopharmacol 16(10):2145-63.

Cenquizca LA, Swanson LW (2007). Spatial organization of direct hippocampal field CA1 axonal projections to the rest of the cerebral cortex. Brain Res Rev 56(1):1-26.

Cho RY, Konecky RO, Carter CS (2006), Impairments in frontal cortical gamma synchrony and cognitive control in schizophrenia. Proc Natl Acad Sci U S A 103(52):19878-83. 
Cochran SM, Kennedy M, McKerchar CE, Steward LJ, Pratt, JA, Morris BJ (2003), Induction of metabolic hypofunction and neurochemical deficits after chronic intermittent exposure to phencyclidine: differential modulation by antipsychotic drugs. Neuropsychopharmacology 28(2):265-75.

Danos P, Baumann B, Bernstein HG, Franz M, Stauch R, Northoff G, Krell D, Falkai P, Bogerts B (1998), Schizophrenia and anteroventral thalamic nucleus: selective decrease of parvalbumin-immunoreactive thalamocortical projection neurons. Psychiatry Res 82(1):1-10.

Daviss SR, Lewis DA (1995), Local circuit neurons of the prefrontal cortex in schizophrenia: selective increase in the density of calbindin-immunoreactive neurons. Psychiatry Res 59(1-2):81-96.

De Leonibus E, Mele A, Oliverio A, Pert A (2002), Distinct pattern of c-fos mRNA expression after systemic and intra-accumbens amphetamine and MK-801. Neuroscience 115(1):67-78.

DeFelipe J (1997), Types of neurons, synaptic connections and chemical characteristics of cells immunoreactive for calbindin-D28K, parvalbumin and calretinin in the neocortex. J Chem Neuroanat 14(1):1-19.

DeFelipe J, González-Albo MC, Del Río MR, Elston GN (1999), Distribution and patterns of connectivity of interneurons containing calbindin, calretinin, and parvalbumin in visual areas of the occipital and temporal lobes of the macaque monkey. J Comp Neurol 412(3):515-26.

Dietz DM, Kennedy PJ, Sun H, Maze I, Gancarz AM, Vialou V, Koo JW, Mouzon E, Ghose S, Tamminga CA, Nestler EJ (2014), $\triangle$ FosB induction in prefrontal cortex by antipsychotic drugs is associated with negative behavioral outcomes. Neuropsychopharmacology 39(3):538-44.

Dragunow M, Faull R (1989), The use of c-Fos as a metabolic marker in neuronal pathway tracing. J Neurosci Methods 29:261-265.

Druga R (2009), Neocortical Inhibitory System. Folia Biol (Praha) 217:201-217. 
Eyles DW, Mcgrath JJ, Reynolds GP (2002), Neuronal calcium-binding proteins and schizophrenia. Schizophr Res 57(1):27-34.

Fung SJ, Fillman SG, Webster MJ, Shannon Weickert C (2014). Schizophrenia and bipolar disorder show both common and distinct changes in cortical interneuron markers. Schizophr Res 155(1-3):26-30.

Fung SJ, Webster MJ, Sivagnanasundaram S, Duncan C, Elashoff M, Weickert CS (2010), Expression of interneuron markers in the dorsolateral prefrontal cortex of the developing human and in schizophrenia. Am J Psychiatry 167(12):1479-88.

Fuster JM (2008) The Prefrontal Cortex 4th ed. Academic press London 7-58.

Gao XM, Hashimoto T, Tamminga CA (1998), Phencyclidine (PCP) and dizocilpine (MK801) exert timedependent effects on the expression of immediate early genes in rat brain. Synapse 29(1):14-28.

Gao XM, Shirakawa O, Du F, Tamminga CA (1993) Delayed regional metabolic actions of phencyclidine Eur J Pharmacol 241(1):7-15.

Gilmour G, Dix S, Fellini L, Gastambide F, Plath N, Steckler T, Talpos J, Tricklebank M (2012), NMDA receptors, cognition and schizophrenia--testing the validity of the NMDA receptor hypofunction hypothesis. Neuropharmacology 62(3):1401-12.

Gonchar Y, Burkhalter A (1997), Three distinct families of GABAergic neurons in rat visual cortex. Cereb Cortex $7(4): 347-58$.

Gonzalez-Burgos G, Cho RY, Lewis DA (2015), Alterations in cortical network oscillations and parvalbumin neurons in schizophrenia. Biol Psychiatry 77(12):1031-40.

Gonzalez-Burgos G, Lewis DA (2012), NMDA receptor hypofunction, parvalbumin-positive neurons, and cortical gamma oscillations in schizophrenia. Schizophr Bull 38(5):950-7. 
Gotoh L, Kawanami N, Nakahara T, Hondo H, Motomura K, Ohta E, Kanchiku I, Kuroki T, Hirano M, Uchimura $H(2002)$, Effects of the adenosine $A(1)$ receptor agonist $N(6)$-cyclopentyladenosine on phencyclidineinduced behavior and expression of the immediate-early genes in the discrete brain regions of rats. Brain Res Mol Brain Res 100(1-2):1-12.

Griffiths MR, Mitchell IJ, Cooper AJ (1999), Phencyclidine induces D-1 dopamine receptor mediated Fos-like immunoreactivity in discretely localised populations of striatopallidal and striatoentopeduncular neurons in the rat. Brain Res 821(1):177-89.

Habara T, Hamamura T, Miki M, Ohashi K, Kuroda S (2001), M100907, a selective 5-HT(2A) receptor antagonist, attenuates phencyclidine-induced Fos expression in discrete regions of rat brain. Eur J Pharmaco 417(3):189-94.

Haggerty GC, Forney RB, Johnson JM (1984), The effect of a single administration of phencyclidine on behavior in the rat over a 21-day period. Toxicol Appl Pharmacol 75(3):444-53.

Hashimoto T, Arion D, Unger T, Maldonado-Avilés JG, Morris HM, Volk DW, Mirnics K, Lewis DA (2008), Alterations in GABA-related transcriptome in the dorsolateral prefrontal cortex of subjects with schizophrenia. Mol Psychiatry 13(2):147-61.

Hashimoto T, Bazmi HH, Mirnics K, Wu Q, Sampson AR, Lewis DA (2008), Conserved regional patterns of GABA-related transcript expression in the neocortex of subjects with schizophrenia. Am J Psychiatry 165(4):479-89.

Hashimoto T, Volk DW, Eggan SM, Mirnics K, Pierri JN, Sun Z, Sampson AR, Lewis DA (2003), Gene expression deficits in a subclass of GABA neurons in the prefrontal cortex of subjects with schizophrenia. J Neurosci 23(15):6315-26.

Jones EG, Hendry SH (1989), Differential calcium-binding protein immunoreactivity distinguishes classes of relay neurons in monkey thalamic nuclei. Eur J Neurosci 1(3):222-246. 
Homayoun H, Moghaddam B (2007), NMDA receptor hypofunction produces opposite effects on prefrontal cortex interneurons and pyramidal neurons. J Neurosci 27(43):11496-500.

Hussain N, Flumerfelt BA, Rajakumar N (2001), Glutamatergic regulation of haloperidol-induced c-fos expression in the rat striatum and nucleus accumbens. Neuroscience 102(2):391-9.

lasevoli F, Buonaguro EF, Sarappa C, Marmo F, Latte G, Rossi R, Eramo A, Tomasetti C, de Bartolomeis A (2014), Regulation of postsynaptic plasticity genes' expression and topography by sustained dopamine perturbation and modulation by acute memantine: relevance to schizophrenia. Prog Neuropsychopharmacol Biol Psychiatry 3;54:299-314.

Imre G, Fokkema DS, Den Boer JA, Ter Horst GJ (2006), Dose-response characteristics of ketamine effect on locomotion, cognitive function and central neuronal activity. Brain Res Bull 69(3):338-45.

Iritani S, Kuroki N, Ikeda K, Kazamatsuri H (1999), Calbindin immunoreactivity in the hippocampal formation and neocortex of schizophrenics. Prog Neuropsychopharmacol Biol Psychiatry 23(3):409-21.

Jackson ME, Homayoun H, Moghaddam B (2004), NMDA receptor hypofunction produces concomitant firing rate potentiation and burst activity reduction in the prefrontal cortex. Proc Natl Acad Sci U S A 101(22):8467-72.

Javitt DC, Steinschneider M, Schroeder CE, Arezzo JC (1996), Role of cortical N-methyl-D-aspartate receptors in auditory sensory memory and mismatch negativity generation: implications for schizophrenia. Proc Natl Acad Sci U S A 93(21):11962-7.

Javitt DC, Zukin SR (1991), Recent advances in the phencyclidine model of schizophrenia. Am J Psychiatry 148(10):1301-8.

Javitt DC, Zukin SR, Heresco-Levy U, Umbricht D (2012), Has an Angel Shown the Way? Etiological and Therapeutic Implications of the PCP/NMDA Model of Schizophrenia. Schizophr Bull 38(5):958-66. 
Jodo E, Suzuki Y, Katayama T, Hoshino KY, Takeuchi S, Niwa S, Kayama Y (2005), Activation of medial prefrontal cortex by phencyclidine is mediated via a hippocampo-prefrontal pathway. Cereb cortex $15(5): 663-9$

Jodo E (2013), The role of the hippocampo-prefrontal cortex system in phencyclidine-induced psychosis: A model for schizophrenia. J Physiol Paris 107(6):434-40.

Kalinichev M, Robbins MJ, Hartfield EM, Maycox PR, Moore SH, Savage KM, Austin NE, Jones DN (2008), Comparison between intraperitoneal and subcutaneous phencyclidine administration in SpragueDawley rats: a locomotor activity and gene induction study. Prog NeuroPsychopharmacol Biolog Psychiatry 32(2):414-22.

Kargieman L, Santana N, Mengod G, Celada P, Artigas F (2007), Antipsychotic drugs reverse the disruption in prefrontal cortex function produced by NMDA receptor blockade with phencyclidine. Proc Natl Acad Sci U S A 104(37):14843-8.

Kargieman L, Santana N, Mengod G, Celada P, Artigas F (2008), NMDA antagonist and antipsychotic actions in cortico-subcortical circuits. Neurotox Res 14(2-3):129-40.

Kawaguchi Y, Kubota Y (1997), GABAergic cell subtypes and their synaptic connections in rat frontal cortex. Cereb Cortex 7(6):476-86.

Keilhoff G, Becker A, Grecksch G, Wolf G, Bernstein H-G (2004), Repeated application of ketamine to rats induces changes in the hippocampal expression of parvalbumin, neuronal nitric oxide synthase and cFOS similar to those found in human schizophrenia. Neuroscience 126(3):591-8.

Kehrer C, Maziashvili N, Dugladze T, Gloveli T (2008), Altered Excitatory-Inhibitory Balance in the NMDAHypofunction Model of Schizophrenia. Front Mol Neurosci 8;1:6. 
Kiss T, Hoffmann WE, Scott L, Kawabe TT, Milici AJ, Nilsen EA, Hajós M (2011), Role of Thalamic Projection in NMDA Receptor-Induced Disruption of Cortical Slow Oscillation and Short-Term Plasticity. Front Psychiatry 4;2:14.

Kolb B, Pellis S, Robinson TE. (2004), Plasticity and functions of the orbital frontal cortex. Brain Cogn 55(1):104-15.

Korotkova T, Fuchs EC, Ponomarenko A, von Engelhardt J, Monyer H (2010), NMDA receptor ablation on parvalbumin-positive interneurons impairs hippocampal synchrony, spatial representations, and working memory. Neuron 68(3):557-69.

Krystal JH, Karper LP, Seibyl JP, Freeman GK, Delaney R, Bremner JD, Heninger GR, Bowers MB Jr, Charney DS (1994). Subanesthetic effects of the noncompetitive NMDA antagonist ketamine in humans Psychotomimetic, perceptual, cognitive, and neuroendocrine responses. Arch Gen Psychiatry 51(3):199-214.

Lahti AC, Koffel B, LaPorte D, Tamminga CA (1995), Subanesthetic doses of ketamine stimulate psychosis in schizophrenia. Neuropsychopharmacol 13(1):9-19.

Lewis DA (2012), Cortical circuit dysfunction and cognitive deficits in schizophrenia--implications for preemptive interventions. Eur J Neurosci 35(12):1871-8.

Lewis DA (2014), Inhibitory neurons in human cortical circuits: substrate for cognitive dysfunction in schizophrenia. Curr Opin Neurobiol 26:22-6.

Lewis DA, Curley AA, Glausier JR, Volk DW (2012), Cortical parvalbumin interneurons and cognitive dysfunction in schizophrenia. Trends Neurosci 35(1):57-67.

Lewis DA, Hashimoto T, Morris HM (2008), Cell and receptor type-specific alterations in markers of GABA neurotransmission in the prefrontal cortex of subjects with schizophrenia. Neurotox Res 14(2-3):23748. 
Liposits Z, Sétáló G, Flerkó B (1984), Application of the silver-gold intensified 3,3'-diaminobenzidine chromogen to the light and electron microscopic detection of the luteinizing hormone-releasing hormone system of the rat brain. Neuroscience 13(2):513-25.

López Hill X, Scorza MC (2012), Role of the anterior thalamic nucleus in the motor hyperactivity induced by systemic MK-801 administration in rats. Neuropharmacology 62(7):2440-6.

López-Gil X, Babot Z, Amargós-Bosch M, Suñol C, Artigas F, Adell A (2007), Clozapine and haloperidol differently suppress the MK-801-increased glutamatergic and serotonergic transmission in the medial prefrontal cortex of the rat. Neuropsychopharmacology 32(10):2087-97.

Luby ED, Cohen BD, Rosenbaum G, Gottlieb JS, Kelley R (1959), Study of a new schizomimetic drug - Sernyl. AMA Arch Neurol Psychiatry 81(3):363-9.

Ludbrook J (1998), Multiple comparison procedures updated. Clin Exp Pharmacol Physiol 25(12):1032-7.

Malhotra AK, Adler CM, Kennison SD, Elman I, Pickar D, Breier A (1997), Clozapine blunts N-methyl-Daspartate antagonist-induced psychosis: a study with ketamine. Biol Psychiatry 42(8):664-8.

Markram H, Toledo-Rodriguez M, Wang Y, Gupta A, Silberberg G, Wu C (2004), Interneurons of the neocortical inhibitory system. Nat Rev Neurosci 5(10):793-807.

McKibben CE, Jenkins TA, Adams HN, Harte MK, Reynolds GP (2010), Effect of pretreatment with risperidone on phencyclidine-induced disruptions in object recognition memory and prefrontal cortex parvalbumin immunoreactivity in the rat. Behav Brain Res 208(1):132-6.

Meltzer HY, Massey BW (2011) The role of serotonin receptors in the action of atypical antipsychotic drugs. Curr Opin Pharmacol 11(1):59-67.

Meltzer HY, Rajagopal L, Huang M, Oyamada Y, Kwon S, Horiguchi M (2013) Translating the N-methyl-Daspartate receptor antagonist model of schizophrenia to treatments for cognitive impairment in schizophrenia. Int J Neuropsychopharmacol 16(10):2181-94. 
Mikkelsen JD, Vrang N, Mrosovsky N (1998), Expression of Fos in the circadian system following nonphotic stimulation. Brain Res Bull 47(4):367-76.

Minzenberg MJ, Firl AJ, Yoon JH, Gomes GC, Reinking C, Carter CS (2010), Gamma oscillatory power is impaired during cognitive control independent of medication status in first-episode schizophrenia. Neuropsychopharmacology 35(13):2590-9.

Minzenberg MJ, Laird AR, Thelen S, Carter CS, Glahn DC (2009), Meta-analysis of 41 functional neuroimaging studies of executive function in schizophrenia. Arch Gen Psychiatry 66(8):811-22.

Mitelman SA, Shihabuddin L, Brickman AM, Hazlett EA, Buchsbaum MS (2005), Volume of the cingulate and outcome in schizophrenia. Schizophr Res 72(2-3):91-108.

Moreau AW, Kullmann DM (2013), NMDA receptor-dependent function and plasticity in inhibitory circuits. Neuropharmacology 74:23-31.

Morris BJ, Cochran SM, Pratt JA (2005), PCP: from pharmacology to modelling schizophrenia. Curr Opin Pharmacol 5(1):101-6.

Morrow BA, Elsworth JD, Roth RH (2007), Repeated phencyclidine in monkeys results in loss of parvalbumincontaining axo-axonic projections in the prefrontal cortex. Psychopharmacology 192(2):283-90.

Newcomer JW, Farber NB, Jevtovic-Todorovic V, Selke G, Melson AK, Hershey T, Craft S, Olney JW (1999), Ketamine-induced NMDA receptor hypofunction as a model of memory impairment and psychosis. Neuropsychopharmacology 20(2):106-18.

Näkki R, Sharp FR, Sagar SM, Honkaniemi J (1996), Effects of phencyclidine on immediate early gene expression in the brain. J Neurosci Res 45(1):13-27.

Paxinos G and Watson C (2004) The rat brain in stereotaxic coordinates 5th ed. Academic Press. 
Price JL (2007), Definition of the orbital cortex in relation to specific connections with limbic and visceral structures and other cortical regions. Ann N Y Acad Sci 1121:54-71.

Purcell SM, Moran JL, Fromer M, Ruderfer D, Solovieff N, Roussos P, O'Dushlaine C, Chambert K, Bergen SE, Kähler A, Duncan L, Stahl E, Genovese G, Fernández E, Collins MO, Komiyama NH, Choudhary JS, Magnusson PK, Banks E, Shakir K, Garimella K, Fennell T, DePristo M, Grant SG, Haggarty SJ, Gabriel S, Scolnick EM, Lander ES, Hultman CM, Sullivan PF, McCarroll SA, Sklar P (2014), A polygenic burden of rare disruptive mutations in schizophrenia. Nature 13;506(7487):185-90.

Rujescu D, Bender A, Keck M, Hartmann AM, Ohl F, Raeder H, Giegling I, Genius J, McCarley RW, Möller HJ, Grunze H (2006), A pharmacological model for psychosis based on N-methyl-D-aspartate receptor hypofunction: molecular, cellular, functional and behavioral abnormalities. Biol Psychiatry 59(8):7219.

Sadikot AF, Sasseville R (1997), Neurogenesis in the Mammalian Neostriatum and Nucleus Accumbens: parvalbumin-immunoreactive GABAergic interneurons. J Comp Neurol 389(2):193-211.

Santana N, Troyano-Rodriguez E, Mengod G, Celada P, Artigas F (2011), Activation of thalamocortical networks by the N-methyl-D-aspartate receptor antagonist phencyclidine: reversal by clozapine. Biol Psychiatry 69(10):918-27.

Sato D, Umino A, Kaneda K, Takigawa M, Nishikawa T (1997), Developmental changes in distribution patterns of phencyclidine-induced c-Fos in rat forebrain. Neurosci Lett 239(1):21-4.

Sohal VS, Zhang F, Yizhar O, Deisseroth K (2009), Parvalbumin neurons and gamma rhythms enhance cortical circuit performance. Nature 459(7247):698-702.

Suzuki Y, Jodo E, Takeuchi S, Niwa S, Kayama Y (2002), Acute administration of phencyclidine induces tonic activation of medial prefrontal cortex neurons in freely moving rats. Neuroscience 114(3):769-79. 
Tanaka DH, Toriumi K, Kubo K, Nabeshima T, Nakajima KJ (2011) GABAergic precursor transplantation into the prefrontal cortex prevents phencyclidine-induced cognitive deficits. J Neurosci 31(40):14116-25.

Thomsen MS, Christensen DZ, Hansen HH, Redrobe JP, Mikkelsen JD (2009), Alpha(7) Nicotinic acetylcholine receptor activation prevents behavioral and molecular changes induced by repeated phencyclidine treatment. Neuropharmacology 56(6-7):1001-9.

Thomsen MS, Hansen HH, Mikkelsen JD (2010), Opposite effect of phencyclidine on activity-regulated cytoskeleton-associated protein $(\mathrm{Arc})$ in juvenile and adult limbic rat brain regions. Neurochem Int $56(2): 270-5$.

Uhlhaas PJ, Singer W (2010), Abnormal neural oscillations and synchrony in schizophrenia. Nat Rev Neurosci 11(2):100-13.

Van Groen T, Wyss JM (2003), Connections of the retrosplenial granular b cortex in the rat. J Comp Neurol 463(3):249-63.

Vann SD, Aggleton JP, Maguire EA (2009), What does the retrosplenial cortex do? Nat Rev Neurosci 10(11):792-802.

Volk DW, Austin MC, Pierri JN, Sampson AR, Lewis DA (2000), Decreased glutamic acid decarboxylase 67 messenger RNA expression in a subset of prefrontal cortical gamma-amminobutyric acid neurons in subjects with schizophrenia. Arch Gen Psychiatry 57(3):237-45.

Vollenweider FX, Leenders KL, Scharfetter C, Antonini A, Maguire P, Missimer J, Angst (1997) Metabolic hyperfrontality and psychopathology in the ketamine model of psychosis using positron emission tomography (PET) and [18F]fluorodeoxyglucose (FDG) J Eur Neuropsychopharmacol 7(1):9-24.

Väisänen J, Ihalainen J, Tanila H, Castrén E (2004), Effects of NMDA-receptor antagonist treatment on c-fos expression in rat brain areas implicated in schizophrenia. Cell Mol Neurobiol 24(6):769-80. 
Woo T-U W, Kim AM, Viscidi E (2008), Disease-specific alterations in glutamatergic neurotransmission on inhibitory interneurons in the prefrontal cortex in schizophrenia. Brain Res 1218:267-77.

Zhang Y, Llinas RR, Lisman JE (2009), Inhibition of NMDARs in the nucleus reticularis of the thalamus produces delta frequency bursting. Front Neural Circuits 3:20.

Zhang Y, Yoshida T, Katz DB, Lisman JE (2012), NMDAR antagonist action in thalamus imposes $\delta$ oscillations on the hippocampus. J Neurophysiol 107(11):3181-9.

Zhang ZJ, Reynolds GP (2002), A selective decrease in the relative density of parvalbumin-immunoreactive neurons in the hippocampus in schizophrenia. Schizophr Res 55(1-2):1-10. 


\section{FIGURE LEGENDS}

Figure 1. Schematic diagrams of representative coronal brain sections selected for immunohistochemical analysis. Frames delineate the areas analysed within each region of interest: (1) prelimbic prefrontal cortex (PrL); (2) infralimbic prefrontal cortex (IL); (3) cingulate cortex 1 (Cg1); (4) primary and secondary motor cortex (M1/M2); (5) primary somatosensory cortex (S1); (6) ventrolateral orbitofrontal cortex (VLO); (7) nucleus accumbens shell (NAc shell); (8) nucleus accumbens core (NAc core); (9) caudate putamen (CPu); (10) retrosplenial cortex (RS); (11) field CA1 of the hippocampus (CA1); (12) mediodorsal thalamus (MD). Left diagram: $3.00 \mathrm{~mm}$ from bregma; middle diagram: $1.80 \mathrm{~mm}$ from bregma; right diagram: $-3.36 \mathrm{~mm}$ from bregma. (Diagrams modified from Paxinos and Watson $5^{\text {th }}$ ed. 2004).

Figure 2. c-Fos localisation after PCP or vehicle administration. Representative micrographs (100x magnification; scale bar, $250 \mu \mathrm{m}$ ) of sections labelled with c-Fos antibody (dark nuclei) in different brain regions of rats treated with vehicle (saline) or PCP $(10 \mathrm{mg} / \mathrm{kg})$. The black masks in images of RS, MD and CA1 outline the areas analysed. (Note that RS, MD and CA1 were reacted with $D A B-n i c k e l$, whereas all other regions were reacted with $D A B)$.

Figure 3. Bar graph showing c-Fos-IR per area in different brain regions of rats treated with vehicle (saline) $(\mathrm{N}=8)$ or $\mathrm{PCP}(10 \mathrm{mg} / \mathrm{kg})(\mathrm{N}=9) .{ }^{*} \mathrm{P}<0.05$ and $* * * \mathrm{P}<0.001$. (Note that $\mathrm{RS}, \mathrm{MD}$ and CA1 were reacted with $D A B$-nickel, whereas all other regions were reacted with $D A B$ resulting in differences in staining-intensity and hence not directly comparable c-Fos-IR levels). 
Figure 4. PV and c-Fos colocalisation after PCP or vehicle administration. Representative micrographs (400x magnification; scale bar, $65 \mu \mathrm{m}$ ) of sections double-labelled with PV (brown) and c-Fos (dark nuclei) antibodies in different brain regions of rats treated with vehicle (saline) or PCP $(10 \mathrm{mg} / \mathrm{kg})$. Black arrows indicate double-labelled cells.

Figure 5. Bar graph showing the relative number of PV-IR cells, which were also c-Fos-IR, in different brain regions of rats treated with vehicle (saline) $(\mathrm{N}=8)$ or PCP $(10 \mathrm{mg} / \mathrm{kg})(\mathrm{N}=9)$. $P<0.001$. N.D., not detectable.

Figure 6. $\mathrm{CB}$ and $\mathrm{C}-$ Fos colocalisation after $\mathrm{PCP}$ or vehicle administration. (A) Representative micrographs (400x magnification; scale bar, $65 \mu \mathrm{m}$ ) of sections double-labelled with $\mathrm{CB}$ (brown) and c-Fos (dark nuclei) antibodies in different brain regions of rats treated with vehicle (saline) or PCP (10 mg/kg). (B) Bar graph showing the relative number of CB-IR cells, which were also cFos-IR, in different brain regions of rats treated with vehicle (saline) $(\mathrm{N}=8)$ or PCP $(10 \mathrm{mg} / \mathrm{kg}$ ) $(\mathrm{N}=9) .{ }^{* * *} \mathrm{P}<0.001$. N.D., not detectable. 